\title{
Mars Exploration Rovers Landing Dispersion Analysis
}

\author{
Philip C. Knocke*, Geoffrey G. Wawrzyniak ${ }^{\dagger}$, Brian M. Kennedy ${ }^{\star}$ \\ Jet Propulsion Laboratory, California Institute of Technology, Pasadena, California, 91109 \\ and \\ Prasun N. Desai ${ }^{\S}$ \\ NASA Langley Research Center, Hampton, Virginia, 23681 \\ and \\ Timothy J. Parker ${ }^{* *}$, Matthew P. Golombek ${ }^{\dagger \dagger}$, Thomas C. Duxbury ${ }^{\sharp}$, David M. Kass ${ }^{\S \S}$ \\ Jet Propulsion Laboratory, California Institute of Technology, Pasadena, California, 91109
}

\begin{abstract}
Landing dispersion estimates for the Mars Exploration Rover missions were key elements in the site targeting process and in the evaluation of landing risk. This paper addresses the process and results of the landing dispersion analyses performed for both Spirit and Opportunity. The several contributors to landing dispersions (navigation and atmospheric uncertainties, spacecraft modeling, winds, and margins) are discussed, as are the analysis tools used. JPL's MarsLS program, a MATLAB-based landing dispersion visualization and statistical analysis tool, was used to calculate the probability of landing within hazardous areas. By convolving this with the probability of landing within flight system limits (in-spec landing) for each hazard area, a single overall measure of landing risk was calculated for each landing ellipse. In-spec probability contours were also generated, allowing a more synoptic view of site risks, illustrating the sensitivity to changes in landing location, and quantifying the possible consequences of anomalies such as incomplete maneuvers. Data and products required to support these analyses are described, including the landing footprints calculated by NASA Langley's POST program and JPL's AEPL program, cartographically registered base maps and hazard maps, and flight system estimates of in-spec landing probabilities for each hazard terrain type. Various factors encountered during operations, including evolving navigation estimates and changing atmospheric models, are discussed and final landing points are compared with approach estimates.
\end{abstract}

\footnotetext{
${ }^{*}$ Member of Engineering Staff, Navigation and Mission Design Section, Jet Propulsion Laboratory, 4800 Oak Grove Dr., M/S 264-820, Pasadena, CA 91109

${ }^{\dagger}$ Member of Engineering Staff, Navigation and Mission Design Section, Jet Propulsion Laboratory, 4800 Oak Grove Dr., M/S 264-820, Pasadena, CA 91109

* Member of Engineering Staff, Navigation and Mission Design Section, Jet Propulsion Laboratory, 4800 Oak Grove Dr., M/S 264-321, Pasadena, CA 91109

$\S$ Senior Engineer, Vehicle Analysis Branch, NASA Langley Research Center, M/S 365, Hampton, VA 23681, AIAA Associate Fellow

${ }^{* *}$ Athena Science Team Member, Earth and Space Science Division, Jet Propulsion Laboratory, 4800 Oak Grove Dr., M/S 183-501, Pasadena, CA 91109

${ }^{\#}$ Mars Exploration Program Landing Site Scientist, Earth and Space Science Division, Jet Propulsion Laboratory, 4800 Oak Grove Dr., M/S 183-805, Pasadena, CA 91109

$\$$ Mars Geodesy and Cartography Working Group Chairman, Stardust Project, Jet Propulsion Laboratory, 4800 Oak Grove Dr., M/S 264-379, Pasadena, CA 91109

$\$ \$$ Scientist, Earth and Space Science Division, Jet Propulsion Laboratory, 4800 Oak Grove Dr., M/S 169-237, Pasadena, CA 91109
} 


\section{Introduction}

$\mathrm{T}$ HE Mars Exploration Rover (MER) Project comprised two separately launched spacecraft, named Spirit and Opportunity. Spirit was launched on June 10, 2003, and landed safely on Mars on January 4, 2004, near the center of Gusev crater. Opportunity launched July 8, 2003, and landed successfully in Meridiani Planum, on January 25, 2004. Each mission included plans for as many as six Trajectory Correction Maneuvers (TCMs) to target the correct entry conditions and achieve the desired landing point. Entry was direct (from interplanetary space), prograde, and unguided. At a height of approximately $7.5 \mathrm{~km}$, a parachute was deployed, followed by jettison of the heatshield. The lander was then lowered from the backshell on a bridle, and airbags were inflated, surrounding the lander. Shortly before touchdown, solid rockets on the backshell slowed the spacecraft further, and the lander was cut free from the bridle to bounce and roll to a stop. On the surface, the airbags were deflated and retracted, and the tetrahedron-shaped lander was opened, allowing the rover inside to exit and begin the surface science mission.

A key element during development and operations was the calculation and evolution of the landing footprint, and how that interacted with the capabilities of the flight system to affect total mission risk. A summary of the early history of landing footprint estimates, and how that influenced site selection during development, can be found in Ref. 1. The following paper addresses the issues and results of landing dispersion calculations during late development and through operations of both missions.

\section{Trajectory Analysis Tools}

Two trajectory propagation tools were used for MER landing dispersion analyses: the Program to Optimize Simulated Trajectories (POST) program ${ }^{2}$ developed at the NASA Langley Research Center (LaRC), and the Atmospheric-Entry Powered Landing (AEPL) program $^{* * *}$ developed at the Jet Propulsion Laboratory (JPL). Both programs used the same LaRC-developed aerodynamics database, which provided drag and other aerodynamic coefficients as a function of Mach number and capsule angle-of-attack. Also common between the two programs were the atmospheric density models, ${ }^{1}$ mesoscale wind models, ${ }^{3}$ and the spacecraft parameters. Both programs modeled configuration changes (heatshield separation, airbag inflation, etc.) and non-instantaneous parachute deployment and retro-rocket firing.

The POST trajectory analysis was performed modeling "six degree of freedom" (6DOF) dynamics, in which all forces and torques on the spacecraft are included, from atmospheric interface to parachute deployment. During this portion of the entry, the full set of capsule aerodynamics and mass properties were incorporated in the simulation to accurately model the hypersonic descent. From parachute deployment to landing, "three degree of freedom" (3DOF) dynamics were used, in which only the drag force is modeled and is assumed to act opposite the wind-relative velocity vector. The POST trajectory simulation seamlessly transitions from $6 \mathrm{DOF}$ to $3 \mathrm{DOF}$ dynamics within a single continuous simulation.

Version 4.10C2 of the AEPL program, delivered for MER operations, used 3DOF analyses throughout. (The current version of AEPL also models 6DOF effects.) Because MER used unguided ballistic entries, the 3DOF results from AEPL agreed well with POST's 6DOF/3DOF simulations. AEPL was also used in maneuver design, in conjunction with the navigation cruise trajectory propagation and targeting programs.

Monte Carlo analyses were used to determine the landing footprint. Quantities varied in the Monte Carlo runs typically included 2000 entry states, atmosphere and wind profiles, spacecraft parameters such as entry mass, drag coefficients for the entry capsule, backshell, parachute, and airbags, and (in the case of POST) entry capsule mass moments of inertia and center of mass offsets.

\section{Landing Dispersions: Contributing Factors}

A number of factors influence the geometry of landing footprints on Mars, including declination of the interplanetary approach trajectory, landing site location, and the sense of entry (pro-grade, retro-grade, or polar). All MER entries were pro-grade, with Mars equator-relative declinations of $3.6^{\circ}$ (Spirit) and $2.4^{\circ}$ (Opportunity), and were targeted to sites within $15^{\circ}$ of the equator. These purely geometric characteristics were essentially fixed for a given landing target and launch date, tending to produce long, thin landing ellipses oriented roughly East-West.

The MER landing footprints were also influenced by a number of other factors, specifically interplanetary navigation uncertainties, atmosphere modeling uncertainties, spacecraft modeling uncertainties, winds, and EDL margins. Figure 1 illustrates the relative sizes of landing dispersions for each of these contributing factors. In this

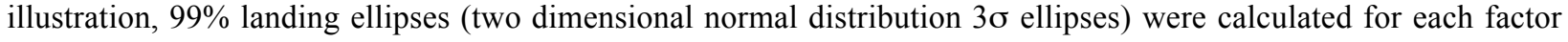

\footnotetext{
${ }^{* * *}$ Klumpp, A. R., Atmospheric-Entry, Powered Landing Simulator V4.10C User's Guide, April 23, 2003 (JPL Internal Document)
} 
for the Spirit mission, and co-located at the Spirit landing target to enhance comparison. Meridiani ellipses were very similar in size but had larger azimuths. (Sizes and orientations for a variety of landing dispersion estimates for both missions are summarized in Section VII, Table 2.)

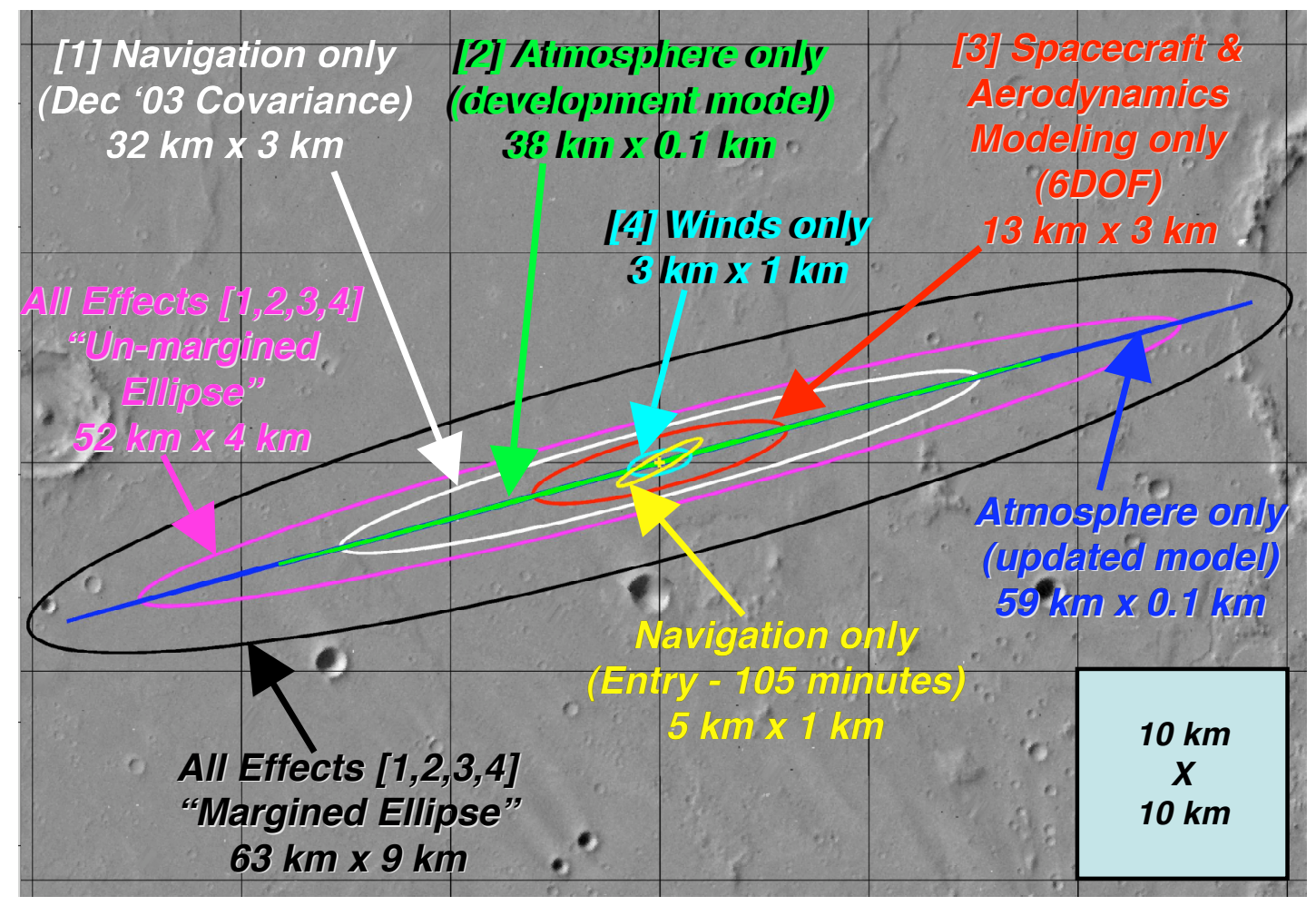

Figure 1: Contributors to Landing Dispersions

\section{A. Navigation Uncertainties}

The accuracy with which the entry state of the spacecraft was determined relative to Mars, given the capabilities of Earth-based radiometric orbit determination and the propagated effects of maneuver execution errors, dominated the landing dispersions for the majority of cruise. Landing footprints became meaningful only during late cruise, by which time the injection errors and planetary protection bias had been removed, the spacecraft was targeted close to its final landing point, and orbit determination uncertainties were small enough to allow visualization of the landing ellipse on a site map.

Figure 1 shows AEPL "navigation only" landing dispersions based on the December 2003 covariance study, and also at the final 2-way data cutoff at Entry - 105 minutes. In both cases, entry states were varied, but the other models (atmosphere, winds, and spacecraft and aerodynamic properties) used nominal values. Navigation errors were strongly dependent on time-to-go to entry, as new data were processed and the propagation uncertainties were reduced. For MER, the use of Delta-differenced One-way Ranging $(\triangle \mathrm{DOR})$ was a key element in producing the small navigation uncertainties seen during operations. ${ }^{4}$

\section{B. Atmospheric Density Variations}

Atmosphere density variations also have a significant effect on landing dispersions. In general, low densities cause the spacecraft to go further down-track, while high densities cause landing to be up-track of the mean. (Both missions entered roughly West-to-East. Lower densities caused landings along the ground track further East; higher densities caused landings West of the mean landing point.) As navigation uncertainties fell during final approach, atmospheric modeling began to dominate the along-track (long axis) dimension of the landing ellipses. Also, atmosphere models were updated during final approach for both Spirit and Opportunity, due to the effects of a dust storm that reached its maximum in mid-December, 2003. Included in Fig. 1 are AEPL "atmosphere only" ellipses, which illustrate the difference between the "development" model (Kass-Schofield v2.4.1) ${ }^{1}$ and an updated model 
used at entry (Kass-Schofield v3.1, based on Mars Global Surveyor (MGS) Thermal Emission Spectrography (TES) observations from December 27, 2003). The updated model had larger uncertainties than the development model. The effect of atmospheric density variations is seen in either case as a very thin ellipse with almost no cross-track dimension.

\section{Spacecraft and Aerodynamic Modeling}

A number of spacecraft properties, including drag coefficients of the parachute, backshell, and lander bodies, and mass of the entry capsule, must also be varied as part of the Monte Carlo analyses. The POST analyses also included variations in the center of mass, mass moments of inertia, and entry attitude, which affected the lift and aerodynamic torque (6DOF effects) on the spacecraft. Typically, all of these effects are much smaller in the along-track direction than the influence of atmosphere modeling uncertainties, as shown in Fig. 1.

\section{Wind Variations}

Uncertainties in winds encountered during EDL also affect landing dispersions. The winds used in these analyses were mesoscale models generated for use by the MER Project. ${ }^{3}$ As illustrated in Fig. 1, this category produces the smallest of the modeled effects in the Monte Carlo results.

\section{E. Un-margined and Margined Ellipses}

All of the above factors are varied independently in a baseline Monte Carlo analysis, producing a landing dispersion (an "un-margined" ellipse, as illustrated in Fig. 1) based on the selected models. Because the contributors are statistically independent, a root sum square of the individual dimensions produces an ellipse nearly identical in size to the combined result. Note that the only significant contributors to cross-track dispersions are navigation uncertainties, spacecraft modeling (6DOF effects in particular), and winds.

\section{EDL Margins}

Proper evaluation of landing site risks required that margins be added to account for other effects that are unmodeled or unknown, or to add robustness in the event flight conditions lay outside the envelope defined by the selected models. EDL margins used during operations included the following effects: density models being in error by $\pm 2.5 \%$ with respect to the models (causing an additional uncertainty of $\pm 2.5 \mathrm{~km}$ in the along-track direction), winds in error by a factor of two with respect to the mesoscale models ( $\pm 4 \mathrm{~km}$ along-track, $\pm 2 \mathrm{~km}$ cross-track), map error $( \pm 1 \mathrm{~km}$ along-track and cross-track), roll stop distance $( \pm 0.5 \mathrm{~km}$ along-track and cross-track), a "targeting margin" to account for the possibility that a post-maneuver ellipse may lie partially outside a desired target ellipse ( $\pm 2 \mathrm{~km}$ along-track), and an arbitrary "control floor" reflecting experience from previous landed missions $( \pm 1 \mathrm{~km}$ along-track and cross-track). The root sum square of these independent effects determined the along-track margin of $\pm 5.5 \mathrm{~km}$, and cross-track margin of $\pm 2.5 \mathrm{~km}$, which were simply added to the "un-margined" $99 \%$ ellipses. The resulting "margined" ellipse (see Fig. 1) also was assumed to be a normally distributed 99\% ellipse. Landing risk was assessed for both ellipse types during final approach.

\section{Landing Site Maps}

During MER development and operations, landing hazards were analyzed and mapped as part of the activities of the MER Landing Sites Working Group. Hazard map images generated for the Spirit and Opportunity landing sites were then converted for use in MarsLS, ${ }^{5}$ a landing site visualization and statistical analysis tool described in Section V. As part of this process, the hazard map for a site was compared with a cartographically registered base map supplied by the Mars Geodesy and Cartography Working Group. The result was an accurately registered representation of the landing site and site hazards, which could be used for landing site safety analysis and TCM decision-making.

\section{A. Hazard Maps and Terrain Classes}

Rigorously modeling all the different terrains in and near the MER landing ellipses $\left(500 \mathrm{~km}^{2}-800 \mathrm{~km}^{2}\right.$ in area) would have been infeasible. Instead, the landing region was divided into a few distinct terrain classes, chosen such that the end-to-end performance of the landing system, in the presence of other site-specific environmental characteristics such as winds, was essentially constant within that terrain class.

Hazard map terrains ${ }^{1}$ were related to simulated terrains that consisted of $3 \mathrm{~m}$ or $10 \mathrm{~m}$ resolution Digital Elevation Maps (DEMs), ${ }^{6}$ several square kilometers in area, generated using stereogrammetry and photoclinometry techniques on MGS Mars Orbiter Camera (MOC) stereo images of representative portions of the landing ellipse. Rocks were randomly scattered on this digital terrain using the standard exponential size-frequency distribution with rock 
abundance percentage derived from Viking Infrared Thermal Mapper (IRTM) data. ${ }^{7,1}$ Hazard terrain maps were generated for each landing site $^{1}$ so that specific DEMs could be extrapolated to similar areas throughout the ellipse and to nearby areas outside the ellipse. The DEMs and rock characteristics were used in the EDL performance simulations to assess landing system performance (including airbag response) on different terrains.

The maps are based on geomorphology and surface roughness and slope derived from MGS MOC and Odyssey Thermal Emission Imaging System (THEMIS) images. For each landing area, four terrains were identified and, where possible, correlated with specific digital elevation models. ${ }^{6}$ The hazard map images delivered for MER operations are shown in Fig. 2. These hazard maps are consistent with the slopes over the ellipses derived from photoclinometry $^{8}$ and the geologic and morphologic maps (e.g., Ref. 9 and Ref. 10). The slopes and relief of the hazard units within the ellipses further demonstrate that the Meridiani site has the lowest slopes, with parts of Gusev having the highest slopes at the $3 \mathrm{~m}-10 \mathrm{~m}$ scale.

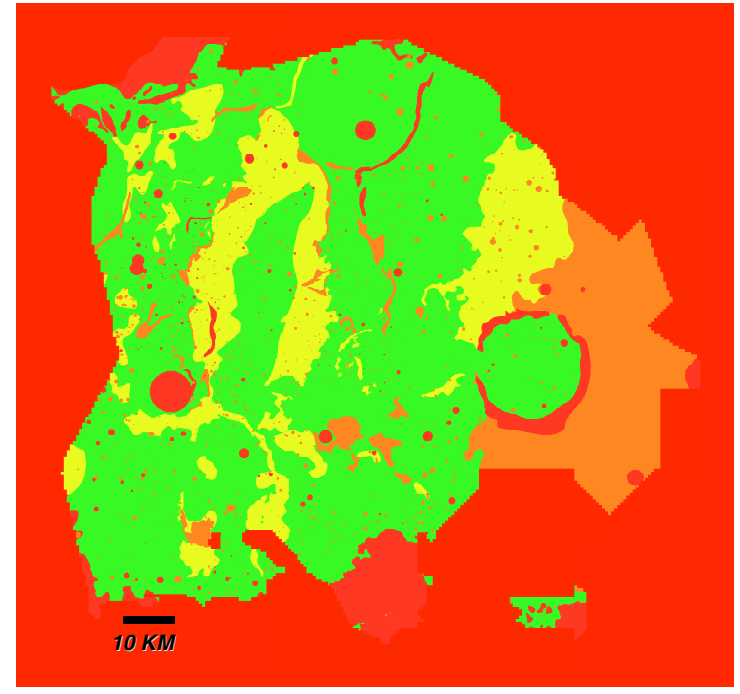

a) Spirit Landing Site Hazard Map (Gusev)

Red $=$ "not survivable, Green = cratered plains Orange $=$ etched terrain, Yellow $=$ secondary craters

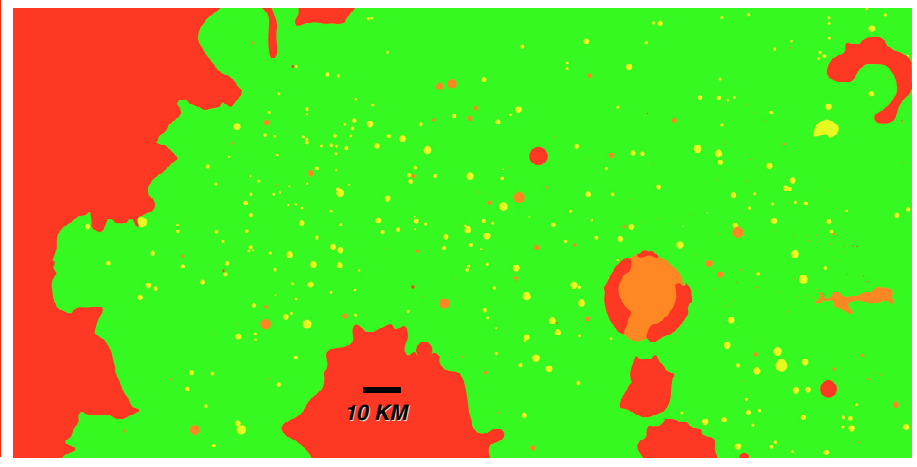

b) Opportunity Landing Site Hazard Map (Meridiani)

Red = "not survivable, Green = plains

Orange $=$ eroded craters, Yellow $=$ subdued craters

Figure 2: Hazard Map Images

Gusev has a background cratered plains unit (marked green in the Gusev map, Fig. 2(a)), a more heavily cratered plains unit (yellow), and an etched terrain unit (orange), which are represented by a $6 \mathrm{~m}$ photoclinometry DEM and two $3 \mathrm{~m}$ photoclinometry DEMs, respectively; two of these units have moderate slopes and the etched terrain has high relief and high slopes. Based on the final pre-entry navigation solution at Gusev, there was an $85 \%$ chance of landing in cratered plains with an RMS slope of approximately $4^{\circ}$, a $13 \%-15 \%$ chance of landing in the slightly rougher, heavily cratered plains terrain $\left(4.5^{\circ}\right.$ RMS slope), and $\leq 1 \%$ chance of landing in the very rough etched terrain (RMS slope of $9.5^{\circ}$ ).

The Meridiani hazard map includes a background terrain (colored green in the Meridiani map, Fig. 2(b)) and subdued low-relief craters (yellow). Both of these units have low slopes and low relief. A number of subdued lowrelief craters ranging in diameter from $0.5 \mathrm{~km}$ to less than $2 \mathrm{~km}$, were mapped within the ellipses. Stereo $10 \mathrm{~m}$ DEMs were used to simulate landing in each of these terrains. The final pre-entry navigation solution at Meridiani Planum yielded a 95\% - 96\% chance of landing in the extremely benign terrain (RMS slope approximately $2^{\circ}$ ) and a $4 \%-5 \%$ chance of landing in fairly smooth subdued craters with an RMS slope of approximately $4^{\circ}$. Engineering analyses indicated that both of these terrain types were virtually indistinguishable from each other in terms of landing safety hazards. (See Section VI for a discussion of the landing system in-spec probabilities assigned to each terrain type.)

An "eroded craters" terrain type, colored orange in Fig. 2(b) was also present at Meridiani. This terrain was characterized by somewhat greater relief and slopes than the subdued craters, and was considered slightly more hazardous. Probabilities of landing in this terrain type were very small $(\leq 0.02 \%)$ at the time of the final navigation solution. 
Both sites have a unit of fresh craters larger than about $200 \mathrm{~m}$ that appear to have fresh bowl shapes and are morphologically distinct from the craters in the units just described. The largest fresh crater in any of the ellipses is approximately $2 \mathrm{~km}$. Because of steep slopes that could spoof the altimeter and cause mis-timed firing of the retrorockets, landing in these areas was assumed to be not survivable in the simulation, even though landing inside many of these craters would be survivable. Total relief of these craters are assumed similar to fresh bowl shaped craters with depths of approximately $20 \%$ and rim heights approximately $4 \%$ of their diameters. The final pre-entry margined landing dispersions at Gusev included 7 fresh craters; the probability of landing in these craters was very small $(\leq 0.2 \%)$. The pre-entry Meridiani margined ellipse included 2 fresh craters; probability of landing in these craters was negligible $(\leq 0.01 \%)$. All "non-survivable" areas, including these fresh craters and Gusev wind hazards (described in Section 2, below), are marked red in Figures 2(a) and 2(b).

Uncertainties in the hazard maps were handled qualitatively, by assessing the confidence in the characterization of the surface and winds in any given area. Areas near the target point and original planning ellipses were considered to be better characterized than more distant areas.

\section{Gusev Wind Hazards}

In certain portions of Gusev crater, predicted near surface winds were capable of inducing horizontal velocities in excess of the landing system's capabilities. In order to fold this into the landing dispersion analyses, certain regions were marked as wind hazardous, independent of the surface hazard assessment. This assessment was based on a statistical analyses of the mesoscale wind models using the intermediate grid (approximately $5 \mathrm{~km}$ horizontal resolution) from the Mars Regional Atmospheric Modeling System (MRAMS) model. ${ }^{11}$ These wind hazard areas, which extended as much as $25 \mathrm{~km}$ inward from the Gusev crater wall, were combined with the surface hazards to create a contiguous "non-survivable" hazard area, colored red in the hazard maps.

The regions of dangerous winds are due to two primary factors: crater rim winds (topographically driven strong updrafts that then interact with the regional flow), and katabatic (slope) winds driven by Ma'adim Valles. For each location, the following parameters were evaluated: effective wind speed, mean turbulent kinetic energy, effective turbulent kinetic energy, and shear. ${ }^{3}$ For each parameter, a cutoff value to flag locations as "not survivable" was selected, based on engineering analyses, representing the point where the flight system was at the border of the dispersed wind profiles used for EDL characterization.

A broad region in the southern part of Gusev crater, characterized by high katabatic winds, was right at the limits of the models. Changing the cutoff values by $10 \%$ could move the boundary of this region significantly.

\section{B. Base Maps}

The Landing Sites Working Group used a variety of data (remotely-sensed visual and infrared images from orbiting spacecraft, and other topographic data) to characterize the landing sites and to select an area for landing, relative to other surface features. Trajectory correction maneuvers, however, are designed to place the spacecraft at a specific location in inertial space, at a specific time, to ensure landing at the desired point. The objective of producing a precision cartographic map of a landing site was to provide a tie between the body-fixed coordinates of the landing site and the inertial coordinate system used for maneuver targeting. The goal was to make this tie to accuracy much better than the accuracy of controlling the landing, as quantified by the landing error ellipse. For MER, this goal translates into having a map tie accurate to $1 \mathrm{~km}(3 \sigma)$ or better.

This level of accuracy was surpassed for both MER sites. The key was to tie imaging data to the local MGS Mars Orbiter Laser Altimeter (MOLA) topographic data. ${ }^{12}$ MOLA produced over 10 billion laser altimetry points that have been tied together in Mars-fixed IAU/IAG 2000 coordinates $^{13}$ of planetocentric latitude, longitude, and radius, with a spatial accuracy of $2 \mathrm{~m}$ and a radial accuracy of $35 \mathrm{~cm}$ for the individual points. The spacing of these points is every $300 \mathrm{~m}$ in latitude with an average longitude spacing of $1.7 \mathrm{~km}$ at the equator going down to $200 \mathrm{~m}$ near the poles.

All MOLA radii points in the MER landing sites were obtained and placed into a sinusoidal map projection having a resolution of $256 \mathrm{pixel} / \mathrm{degree}$ or about $230 \mathrm{~m} / \mathrm{pixel}$. A simple interpolation scheme was used to fill in missing data in the projection to produce local digital terrain models (DTMs) for the two MER sites. Then digital image models (DIMs) were produced by illuminating the DTMs using the lighting conditions that existed for the image datasets that were to be registered to the MOLA DTMs. Viking Orbiter images having $69 \mathrm{~m} / \mathrm{pixel}$ resolution were used for the Gusev Crater. THEMIS infrared daytime images having $100 \mathrm{~m} /$ pixel resolution were used for the site in Meridiani Planum.

In both sites, over 100 precision MOLA-derived cartographic control points were produced by manually measuring small features, mostly craters at the $\mathrm{km}$ level with some positive relief features as well, in the MOLA DIMs to obtain their latitudes, longitudes, and radii in Mars-fixed IAU/IAG 2000 areocentric coordinates. The points were also measured in the imaging data and a full stereo photogrammetric data reduction was performed 
where instrument geometric, alignment, and pointing parameters were estimated along with control point locations and spacecraft orbit parameters.

The results of the stereo photogrammetric process were used together with the MOLA DTM to register each pixel in the Viking Orbiter or THEMIS infrared images to the DTMs to produce precision controlled photomosaics in the form of local DIMs having spatial resolutions at the $100 \mathrm{~m} /$ pixel level (Fig. 3). After landing, the rovers were located in inertial space using direct-to-earth and orbiter relay radiometric tracking of the rovers, and in Mars-fixed DIM coordinates using rover panoramic images to meter level accuracy. ${ }^{\dagger i}$, tht The absolute position errors in the map tie between inertial space and Mars-fixed coordinates were less than $300 \mathrm{~m}$ for the Viking Orbiter based Gusev Crater DIM and less than $150 \mathrm{~m}$ for the THEMIS infrared based Meridiani Planum DIM, meeting the pre-landing requirements of $1 \mathrm{~km}(3 \sigma)$.

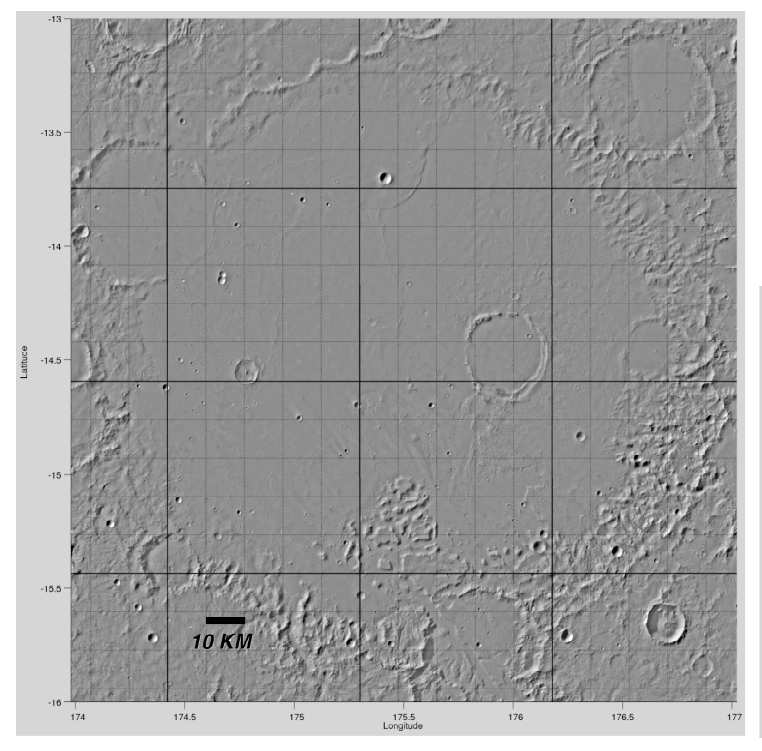

a) Spirit Base Map (Gusev Crater)

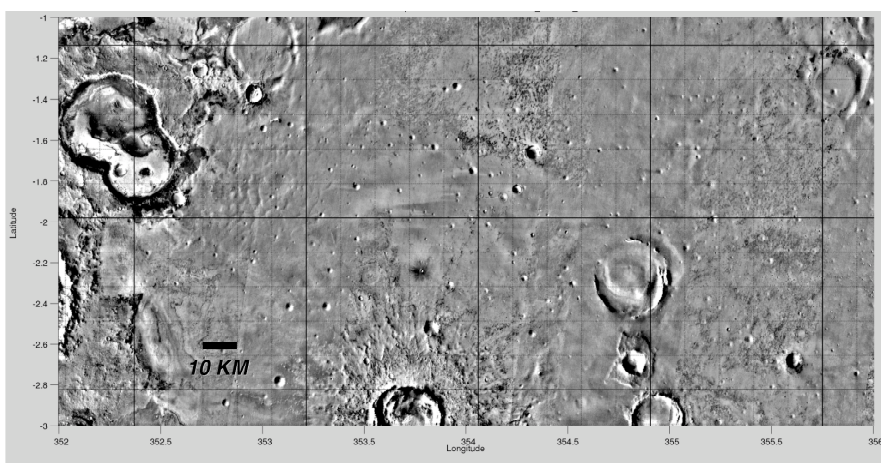

b) Opportunity Base Map (Meridiani Planum)

Figure 3: Base Maps

\section{Landing Site Visualization and Statistical Analyses: MarsLS}

MarsLS ${ }^{5}$ is a MATLAB-based tool created for MER development and operations. The original intent was to provide landing site visualization, whereby latitude/longitude pairs from a Monte Carlo analysis could be placed on various cartographically registered maps. During MER development, the capabilities of this tool were expanded considerably to include various statistical analyses. The result is a general-purpose tool that can accept a variety of inputs and rapidly perform analyses useful in quantifying landing risks. Figures 1 and Figures $3-8$ were all generated using MarsLS.

\section{A. Overview}

One of the mission design requirements for MER was to "provide the capability to display a calibrated image of Mars that contains the target landing site and to display specified latitude and longitude points (from multiple sources) on image." ${ }^{14}$ MATLAB ${ }^{15}$ proved to be the best environment in which to rapidly develop such a graphical user interface (GUI) tool. This tool could take advantage of MATLAB's flexibility, including existing MATLAB functions and GUI capabilities.

The Mars Geodesy and Cartographic Working Group generated MER landing site maps in the NASA Planetary Data Systems (PDS3) ${ }^{\S \S}$ format, Version 3.1. These site maps were calibrated to the MOLA reference surface to

\footnotetext{
T† Golombek, M. P. and Parker, T. J., "Location of Spirit on Mars", MER Localization Memo, 19 Jan. 2004. (JPL Internal Document)

It: Golombek, M. P. and Parker, T. J., "Location of Opportunity on Mars", MER Localization Memo, 2 Feb. 2004. (JPL Internal Document)

$\S \S \S \mathrm{http}: / /$ pds.jpl.nasa.gov
} 
within $1 \mathrm{~km}(3 \sigma)$. They contained the image and information about that image, such as pixel dimensions and latitude and longitude mappings. All images were sinusoidal equal-area projections. Using existing MATLAB functions, MarsLS is able to read these images, properly display them, and correctly map their pixels to Mars areocentric latitude and longitude.

In addition to displaying the calibrated image, MarsLS can overlay a number of different features on the base image. For example, MarsLS is able to read and display a text file of latitude and longitude points, which were often created in AEPL or POST Monte Carlo runs. MarsLS can unwrap those points to a flat surface and create a twodimensional normally distributed ellipse from those points. (The user can specify the statistical nature of the resulting ellipse, i.e. whether it is an $\mathrm{n} \%$ ellipse or an n-sigma ellipse.) Alternatively, the user can import, specify or draw an ellipse, and define the statistical nature of the ellipse. The user can also overlay a grid in degrees or kilometers, draw or specify lines between features to determine surface distance, and specify or draw point locations.

A significant feature of MarsLS is the ability to define or display areas which can be used to indicate hazards or areas of interest. These areas are defined as polygons with latitude and longitude-based vertices. The Statistical Analysis Package in MarsLS uses these area polygons, in conjunction with displayed ellipses, to rapidly calculate probabilities of landing in those areas.

\section{B. Mathematical Basis of the MarsLS Statistical Analysis Package}

Given an ellipse and a polygonal area, the probability $\mathrm{P}$ of landing inside the polygonal region is found by integrating the bi-variate probability distribution function (BvPDF) associated with the ellipse, as follows:

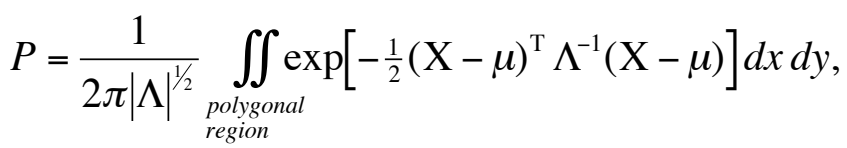

where $\Lambda$ is the two-dimensional covariance described by the ellipse centered at $\mu=\left[\mu_{x}, \mu_{y}\right]^{\mathrm{T}}$ and $\mathrm{X}$ is the vector $[\mathrm{x}, \mathrm{y}]^{\mathrm{T}}$. This integration is non-trivial to perform. Fortunately, a novel algorithm, developed by John Michel at JPL, exists to integrate this function. ${ }^{* * * *, \dagger \dagger \dagger}$ Michel first translates the origin of the system to the center of the ellipse and rescales the new axes by dividing by the standard deviations:

$$
\xi=\left(\mathrm{x}-\mu_{\mathrm{x}}\right) / \sigma_{\mathrm{x}} \text { and } \eta=\left(\mathrm{y}-\mu_{\mathrm{y}}\right) / \sigma_{\mathrm{y}}
$$

This results in a transformed covariance matrix $\Gamma$, equal to the correlation matrix of $\Lambda$. The integral is further simplified by rotating from the $[\xi, \eta]$ axes to axes parallel with the eigen-axes of $\Gamma$. The new system is scaled along the eigen-axes so that the resulting transformed covariance matrix is the identity matrix. The result of all these transformations is summarized in the following set of equations, mapping the original $[\mathrm{x}, \mathrm{y}]$ system to a final $[\mathrm{r}, \mathrm{s}]$ system:

$$
r=\frac{1}{\sqrt{2(1+\rho)}}\left[\frac{x-\mu_{x}}{\sigma_{x}}+\frac{y-\mu_{y}}{\sigma_{y}}\right], \quad s=\frac{1}{\sqrt{2(1-\rho)}}\left[-\frac{x-\mu_{x}}{\sigma_{x}}+\frac{y-\mu_{y}}{\sigma_{y}}\right]
$$

where $\rho$ is the correlation coefficient. In the $[r, s]$, system the integral is greatly simplified. The dispersion ellipse is now a circle with unit radius centered at the origin, and the $\mathrm{r}$ and $\mathrm{s}$ integrations decouple. Also, each polygonal region is transformed to a new polygonal region by the change in coordinates. The probability integral can now be expressed as follows:

$$
P=\frac{1}{2 \pi} \iint_{\substack{\text { new } \\ \text { polygon }}} \exp \left[\left(r^{2}+s^{2}\right) / 2\right] d r d s
$$

\footnotetext{
${ }^{* * * *}$ Michel, J. R., "Users Guide for HAZPRB Computer Program, Including Algorithm Description," JPL Interoffice Memo, 26 Jun. 2000. (JPL Internal Document)

$t_{T \dagger}$ Michel, J. R., "MATLAB Functions for Computing Probabilities of Hitting Circular, Elliptical, or Polygonal Target Regions," JPL Interoffice Memo, 2 Aug. 2002. (JPL Internal Document) 
Integration over the transformed polygonal area is performed by first dividing it into a set of triangles. To integrate over any one of the triangles, the $[\mathrm{r}, \mathrm{s}]$ coordinate system is rotated to be parallel with one side of the triangle, allowing the integral to be expressed as the sum or difference of integrals over two right triangles. The probability of being inside each right triangle can be efficiently computed by converting the double integral of Eq. 4 into an easier one-dimensional integral. The probability for each triangle is computed, and summed to get the cumulative probability for the entire polygonal region.

\section{Hazard Area Generation for MarsLS}

In order for MarsLS to calculate the probability of landing in a hazard area, the hazard maps were processed to provide the polygonal areas described above. The hazard map images were first converted into PDS3 format, and adjusted as needed to provide the correct registration with respect to the base maps. The result was a cartographically registered grayscale image, readable by MarsLS, with unique levels of gray for each hazard type. This image was then read by MarsLS, and a separate MATLAB script was used to outline each hazard area. The output of the script was a text file containing ordered latitude/longitude pairs for each distinct hazard area. The resulting areas could be displayed on any map (or a blank grid) and probability calculations performed. Figures 5 through 8 include examples of such areas displayed on the base map. The colors of the outlined regions correspond to the colors on the hazard map. Some hazards lay entirely within the confines of other hazards, so it was necessary to have both "positive" and "negative" areas to book-keep probabilities properly. Areas outside the regions covered by the hazard map images were, conservatively, set to red or "not survivable".

Other regions not associated with landing hazards were also identified for statistical analysis. These included areas where MOC coverage was available, and, for Meridiani, regions where night-time temperatures were low, potentially affecting mission lifetime. Examples are shown in Figures 7 and 8; white rectangular areas are MOC coverage swaths; black irregular areas are low temperature regions. Probabilities of landing in these areas were assessed as secondary mission risk factors.

\section{Calculation and Use of EDL In-Spec Probabilities}

Rigorously, the total probability of an EDL trajectory remaining within flight system specifications requires evaluation of numerous performance metrics. The MER flight system performance envelope was broad enough, however, that during final approach, the "Entry/Descent" performance (associated with heating rate and integrated heating limits, maximum allowable deceleration, parachute deploy limits on Mach number and dynamic pressure, limitations on heatshield deploy conditions, and minimum acceptable time from chute deploy to landing) was predicted to be $99 \%$ - 100\% in-spec for all but the most anomalous conditions. This expectation was born out during operations.

The great majority of EDL mission risk was associated with the final phase: terminal descent and landing, in particular the final interaction of the flight system with the surface. By combining the capabilities of MarsLS (rapid calculation of the probability of landing in a given hazard type for a given landing dispersion) with a knowledge of flight system consequences (probability of being in-spec for a given hazard type) it became possible to quantify mission risk during final approach, and generate contours for assessing mission risk over a wide area of the landing site.

\section{A. Flight System Capabilities: Terrain-specific In-spec Probabilities}

With one exception, for each terrain type identified in the hazard maps, DEMs were used by the EDL Systems Group in landing simulations. (A DEM for Meridiani's "eroded craters" terrain was never created; the in-spec probability for this hazard type was based on analyses using similar terrain.) These DEMs and other environmental models were used in a suite of high-fidelity programs capable of simulating the entire spacecraft trajectory, including all spacecraft configuration changes and multi-body dynamics and kinematics, from cruise stage separation through bouncing and rolling on the surface. Using these tools, EDL systems analysts identified in-spec probabilities for each unique terrain, taking into account the measurement types available (RADAR altimetry, descent imaging, IMU and accelerometer measurements), the environment (atmospheric density, winds, rock distribution, and terrain slopes), and flight system characteristics (parachute properties, multi-body terminal descent dynamics, retrorocket characteristics, and airbag properties). All results assumed the spacecraft and flight software work as designed (i.e. no workmanship or software errors).

Estimates of the in-spec probabilities for each terrain type were revised continually throughout development and into operations, as updated analyses became available. The terrain-specific in-spec probabilities used during final approach for each mission are summarized in Table 1 . The uncertainties in these numbers are approximately $\pm 2 \%$; 
this value is based on run-to-run simulation variability, and assumes the EDL conditions lie within the modeled envelope of environmental uncertainties.

Table 1 Final Terrain-Specific In-spec Probabilities

\begin{tabular}{|l|c|c|l|c|c|}
\hline \multicolumn{3}{|c|}{ Spirit Landing Site (Gusev Crater) } & \multicolumn{3}{c|}{ Opportunity Landing Site (Meridiani Planum) } \\
\hline \multicolumn{1}{|c|}{ Terrain Type } & $\begin{array}{c}\text { Hazard Map } \\
\text { Color }\end{array}$ & P(in-spec) & Terrain Type & $\begin{array}{c}\text { Hazard } \\
\text { Map Color }\end{array}$ & P(in-spec) \\
\hline Cratered Plains & Green & $97.6 \%$ & Cratered Plains & Green & $99.3 \%$ \\
\hline Heavily Cratered Plains & Yellow & $97.6 \%$ & Subdued Craters & Yellow & $99.3 \%$ \\
\hline Etched Terrain & Orange & $89.4 \%$ & Eroded Craters & Orange & $93 \%$ \\
\hline "Not Survivable" & Red & $0 \%$ & "Not Survivable" & Red & $0 \%$ \\
\hline
\end{tabular}

\section{B. Total In-spec Probabilities}

Given the ability to calculate the probability of landing in any given terrain type (for a specified landing ellipse) and the in-spec rate for each terrain class, it was possible to calculate a total probability of being in-spec for any landing dispersion. This was done by convolving the two sets of probabilities as follows:

$$
\text { Total } \mathrm{P}(\text { in-spec })=\sum_{i} \mathrm{P}(\text { landing in terrain type i }) * \mathrm{P}(\text { in-spec landing for terrain type i) }
$$

In this way, a multitude of analyses (navigation estimates, Monte Carlo EDL trajectory propagation, and flight system environmental interactions) were distilled into a single measure of landing risk, easily updated whenever new landing dispersions became available. During operations, P(in-spec) values for both margined and un-margined ellipses were calculated; the value reported was the smaller of the two.

\section{Probability Contours}

By extending the process, it became possible to contour $\mathrm{P}$ (in-spec) values across a landing site. In MarsLS, landing ellipses were laid down in a grid over the hazard areas. Total in-spec probabilities were then calculated for each ellipse, using Eq. 5. The result was a unique $\mathrm{P}($ in-spec) value associated with the latitude and longitude of the center of each ellipse. Contours were generated using a MATLAB script that employed a two-dimensional interpolation mode selected by the user (nearest neighbor, bilinear, cubic spline, or bicubic) to smooth the in-spec surface. The contours were generated as a type of area file, i.e. ordered sets of latitude/longitude pairs, which could be displayed in MarsLS.

Example contour plots are shown in Fig. 4, using cubic spline interpolation. Margined ellipses were used for this figure, using entry dispersions from cruise covariance studies (assuming TCM-5 occurred two days before entry), in conjunction with the final terrain-specific in-spec probabilities. As expected, the probability contours are highly correlated with the features of the hazard map, in particular the location of red ("non-survivable") hazards. Contour maps like these were useful in identifying optimal areas (from a landing risk standpoint) and for providing insight into landing risk variability across a wide area. This allowed mission planners to understand proximity to probability "cliffs", and to evaluate quickly the risk incurred by anomalous or unplanned events such as an incomplete maneuver.

The MER spacecraft allowed for a variety of maneuver modes to be implemented, depending on the use of the lateral and axial thrusters on the cruise stage. "Vector mode" maneuvers, which used both sets of thrusters, sometimes produced a maneuver "ground path" (locus of possible landing points as a function of maneuver duration) which included regions of low $\mathrm{P}$ (in-spec) values. Alternate maneuver modes, using one or the other thruster type exclusively, produced maneuver ground paths that always increased P(in-spec) but sometimes landed slightly off-target. The probability contours provided a quick, approximate assessment of these options, sometimes allowing certain maneuver modes to be eliminated early in the maneuver development process. 
Gusev was the more challenging site, containing more hazardous areas more closely placed than Meridiani. Even in Gusev, however, as illustrated in Fig. 4(a), optimal regions were relatively large and involved only gradual changes in in-spec probabilities as the center point was moved, particularly in the direction of the major axis of the landing ellipses (roughly East-West). The much more pronounced sensitivity of in-spec probabilities to cross-track (roughly North-South) movement is clearly illustrated. Meridiani is a much more benign landing environment, as illustrated in Fig. 4(b), where the optimal region covers a much larger area.

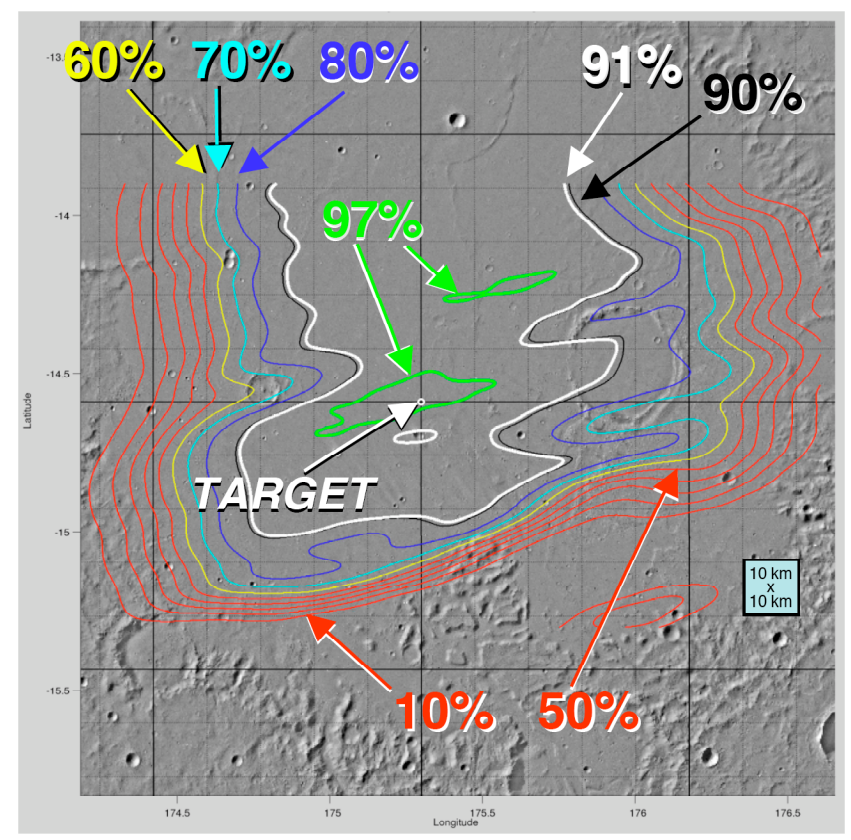

(a) Spirit Landing Site (Gusev Crater)

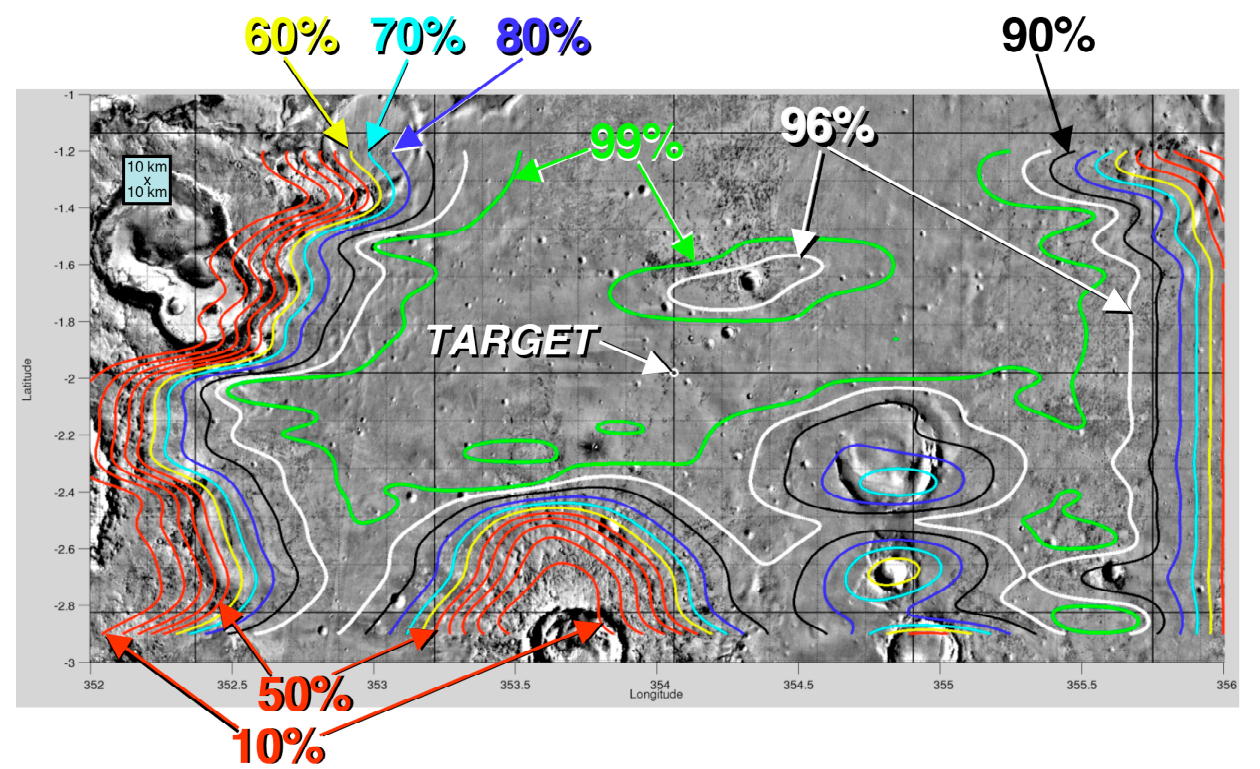

(b) Opportunity Landing Site (Meridiani Planum)

Figure 4: In-spec Probability Contours 


\section{Landing Targets and Requirements}

Selection of the landing sites for MER involved assessments of numerous factors, including science merit, the inherent limitations of the flight system (primarily site altitude, landing dispersions, and landing safety issues), and mission return and mission lifetime. ${ }^{1}$ The landing site targets, i.e. the latitude and longitude navigators would target, were first determined by reviewing the characteristics of the site and selecting a target landing point which caused the landing dispersion ellipse to avoid hazardous areas, while remaining within well-characterized regions of high science value. These targets were periodically revised throughout development, as the consequences of landing in various terrains became better understood and as landing dispersion estimates changed.

Once the MarsLS statistical analysis package became available, the targets were evaluated to see how well landing hazards were being minimized. In July, 2003, Spirit's landing target in Gusev crater was moved approximately $2 \mathrm{~km}$ to the final target location of $-14.59^{\circ}$ areocentric latitude, $175.3^{\circ}$ East longitude (IAU/IAG 2000 frame), based on MarsLS estimates of the optimal location of un-margined and margined TCM-5 ellipses. As indicated in Fig. 4, this target is slightly south of the center of the $97 \%$ in-spec contour. For Meridiani, in-spec probabilities were high enough, and varied so minimally across the landing site, that no change to the landing target ( $-1.98^{\circ}$ areocentric latitude, $354.06^{\circ}$ East longitude) was indicated.

Total landing in-spec probability was one of several factors used for deciding whether or not to perform a trajectory correction maneuver. For Spirit, this factor was "green", i.e. no maneuver was indicated, if P(in-spec) $\geq$ 91\%; for Opportunity, this factor was green if $\mathrm{P}(\mathrm{in}-\mathrm{spec}) \geq 96 \%$. Probability contours for these values are shown as white lines on Fig. 4. These probability levels were approved at the March 2003 Landing Site Peer Review, at which the Gusev and Meridiani sites were selected for MER. (The Gusev site for Spirit was selected provisionally at this meeting, pending additional analyses. Gusev was formally selected in September 2003.)

These probability values were the primary landing site requirements the navigation team used, as part of the maneuver design process. ${ }^{16}$ In this way, landing in-spec probability values (within well-characterized areas of the surface) were being targeted, more than a formal "target ellipse". Prior to launch and periodically throughout cruise, however, covariance studies were used to benchmark landing ellipse estimates for planning purposes.

Table 2 summarizes the landing targets, probability requirements, and estimated landing ellipses for both missions, compared with final landing ellipse estimates. In this table, the landing ellipse properties refer to $99 \%$ margined ellipses, based on expected performance at TCM-5, using the development atmosphere model. All locations are areocentric latitude and East longitude with respect to the IAU/IAG 2000 reference. Azimuth is clockwise with respect to true North.

Table 2 Landing Targets and Requirements. Margined Landing Dispersion Predicts vs Actuals

\begin{tabular}{|l|c|c|}
\hline \multicolumn{1}{|c|}{ Targets and Requirements } & Spirit & Opportunity \\
\hline Landing Target & $-14.59^{\circ}, 175.3^{\circ}$ & $-1.98^{\circ}, 354.06^{\circ}$ \\
\hline Landing P(in-spec) Requirement & $91 \%$ & $96 \%$ \\
\hline
\end{tabular}

\begin{tabular}{|l|c|c|}
\hline \multicolumn{1}{|c|}{ Predicts } & Spirit & Opportunity \\
\hline Landing Dispersions (June/July 2003) & $81 \times 12 \mathrm{~km}, 75^{\circ}$ Azimuth & $81 \times 11 \mathrm{~km}, 83^{\circ}$ Azimuth \\
\hline Landing Dispersions (August 2003) & $78 \times 10 \mathrm{~km}, 75^{\circ}$ Azimuth & $85 \times 11 \mathrm{~km}, 83^{\circ}$ Azimuth \\
\hline Landing Dispersions (December 2003) & $63 \times 9 \mathrm{~km}, 75^{\circ}$ Azimuth & $65 \times 9 \mathrm{~km}, 84^{\circ}$ Azimuth \\
\hline
\end{tabular}

\begin{tabular}{|l|c|c|}
\hline \multicolumn{1}{|c|}{ Actuals } & Spirit & Opportunity \\
\hline Landing Point & $\begin{array}{c}-14.57^{\circ}, 175.5^{\circ} \\
(10 \mathrm{~km} \text { from Target })\end{array}$ & $\begin{array}{c}-1.95^{\circ}, 354.47^{\circ} \\
(25 \mathrm{~km} \text { from Target })\end{array}$ \\
\hline Final Pre-entry Landing P(in-spec) & $97 \%$ & $99 \%$ \\
\hline Final Pre-entry Landing Dispersions & $73 \times 8 \mathrm{~km}, 75^{\circ}$ Azimuth & $71 \times 10 \mathrm{~km}, 86^{\circ}$ Azimuth \\
\hline
\end{tabular}

Navigation targeting performance to the top of the atmosphere was much better than predicted. For example, TCM-5 $3 \sigma$ flight path angle dispersions at the final pre-entry solution were $0.01^{\circ}$ (Spirit) and $0.02^{\circ}($ Opportunity), compared with the December 2003 covariance study estimates of $0.07^{\circ}($ Spirit $)$ and $0.08^{\circ}$ (Opportunity). By the final week of cruise, however, landing ellipse along-track dimensions were dominated by atmospheric dispersions, rather 
than entry state uncertainties. The reason the final landing dispersions were larger than those predicted by the final cruise covariance study, was due to the use of updated atmosphere models with larger dispersions.

\section{Landing Dispersion Results for Spirit and Opportunity}

The final weeks before entry and landing involved similar activities for both missions. Landing dispersions were analyzed starting approximately 1-2 months from entry. Starting about two weeks from entry, landing dispersion assessments, including calculation of in-spec probabilities, were performed daily. In support of the final maneuvers (TCM-4, TCM-5, and TCM-6), analyses were performed for cases with and without maneuvers. Cases without maneuvers used orbit determination estimates only; cases with maneuvers included the propagated effects of modeled maneuver execution errors. POST and AEPL Monte Carlos were used to supply the landing footprints. After landing, radiometric analyses and landmark triangulation were used to determine the final position of the landers. The following results summarize the landing dispersions for both missions during approach, and compare the last pre-entry predicts with the final locations.

\section{A. Spirit}

Figure 5 shows the history of landing dispersions from Entry-29 days (December 5, 2003 Pacific Standard Time (PST)) to Entry (January 3, 2004 PST), using 99\% margined ellipses. This interval starts approximately two weeks after the third TCM was performed. Figure 5(a) shows the interval from December 5 to December 26, using AEPL estimates; each ellipse or group of ellipses is noted with the PST date of the solution. As shown, although the sizes of the landing dispersions decrease rapidly during this time, the location of the center point is extremely constant, varying by less than $1 \mathrm{~km}$. For all of these solutions, the Entry/Descent performance (see Section VI) was $100 \%$ inspec; landing P(in-spec) varied between $38 \%$ and $47 \%$, due largely to the presence of the red hazard boundary very near the center of the landing ellipses.

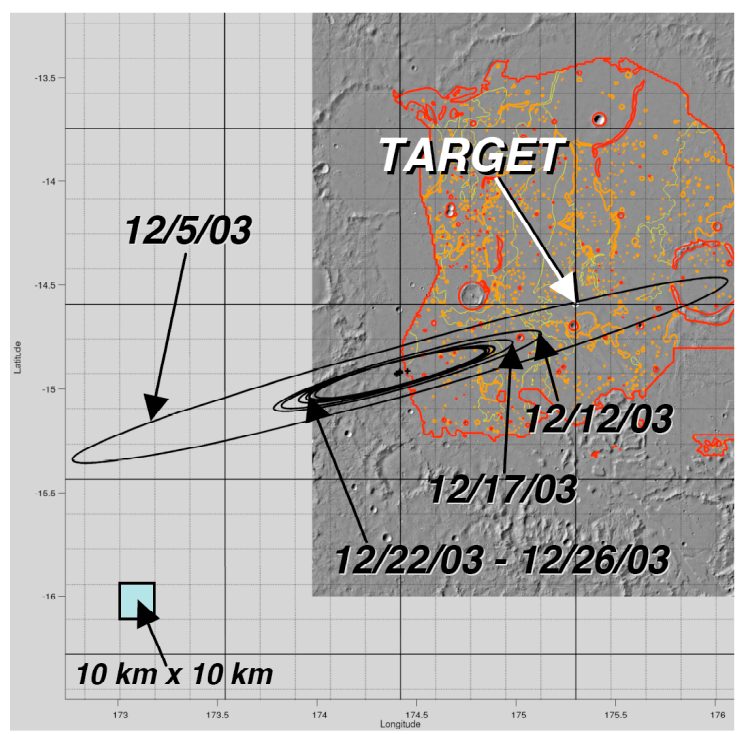

a) Before TCM-4

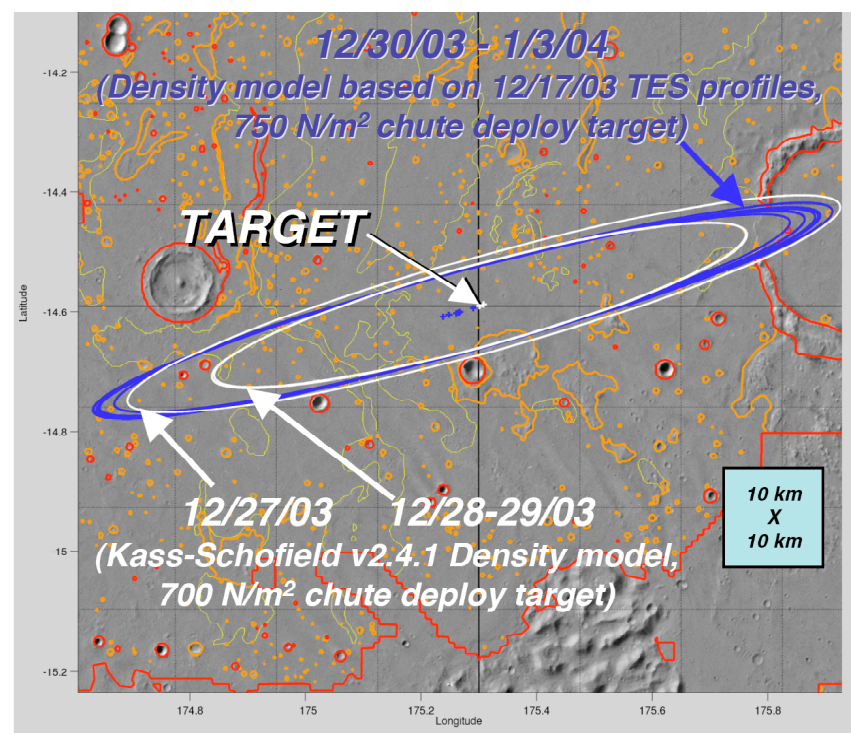

b) After TCM-4

Figure 5: Spirit Landing Dispersions During Approach

Spirit's fourth and final maneuver, TCM-4, occurred 8 days before entry, on December 26, 2003 PST. Figure 5(b) shows Spirit 99\% margined ellipses after TCM-4, using POST estimates. During this interval, changes were made to the density model, to account for observed changes in the atmosphere due to a dust storm. One effect of this change was an erosion in estimated timeline (time between parachute deploy and retrorocket firing), which led to a change in targeted parachute deploy dynamic pressure. Previously set to $700 \mathrm{~N} / \mathrm{m}^{2}$, the chute deploy target was increased to $725 \mathrm{~N} / \mathrm{m}^{2}$. Changes in density model and chute deploy target are color-coded in the figure. Prior to December 30, 2003 the atmosphere models employed for most of development (Kass-Schofield v2.4.1) were used for these analyses. After this date the Kass-Schofield V3.1 model, based on MGS TES observations taken December 27, 2003 were used. In spite of changes to the models and the chute target, the estimated location of the landing 
ellipse centers was relatively constant, moving by only about $3 \mathrm{~km}$ during this time. All post-TCM-4 solutions had Entry/Descent in-spec probabilities of $100 \%$ and landing in-spec probabilities of $97 \%$.

After landing, the inertial position of the landed spacecraft was determined from radiometric analyses using direct-to-Earth Doppler measurements, and UHF Doppler measurements between the rover and the Odyssey spacecraft in Mars orbit. Landmark triangulation, using MOC and descent imaging, determined the final position of the lander with respect to imaged features. Figure 6 shows the POST and AEPL landing ellipses, margined and un-margined, for the final pre-entry landing dispersions, based on two-way radiometric measurements with a data cutoff approximately 105 minutes from Entry. Also shown are the post-entry radiometric and image-relative positions. This figure illustrates the close agreement between dispersions calculated in POST and AEPL. The AEPL ellipses tend to be slightly smaller due to the lack of lift or side forces in the 3DOF analyses.
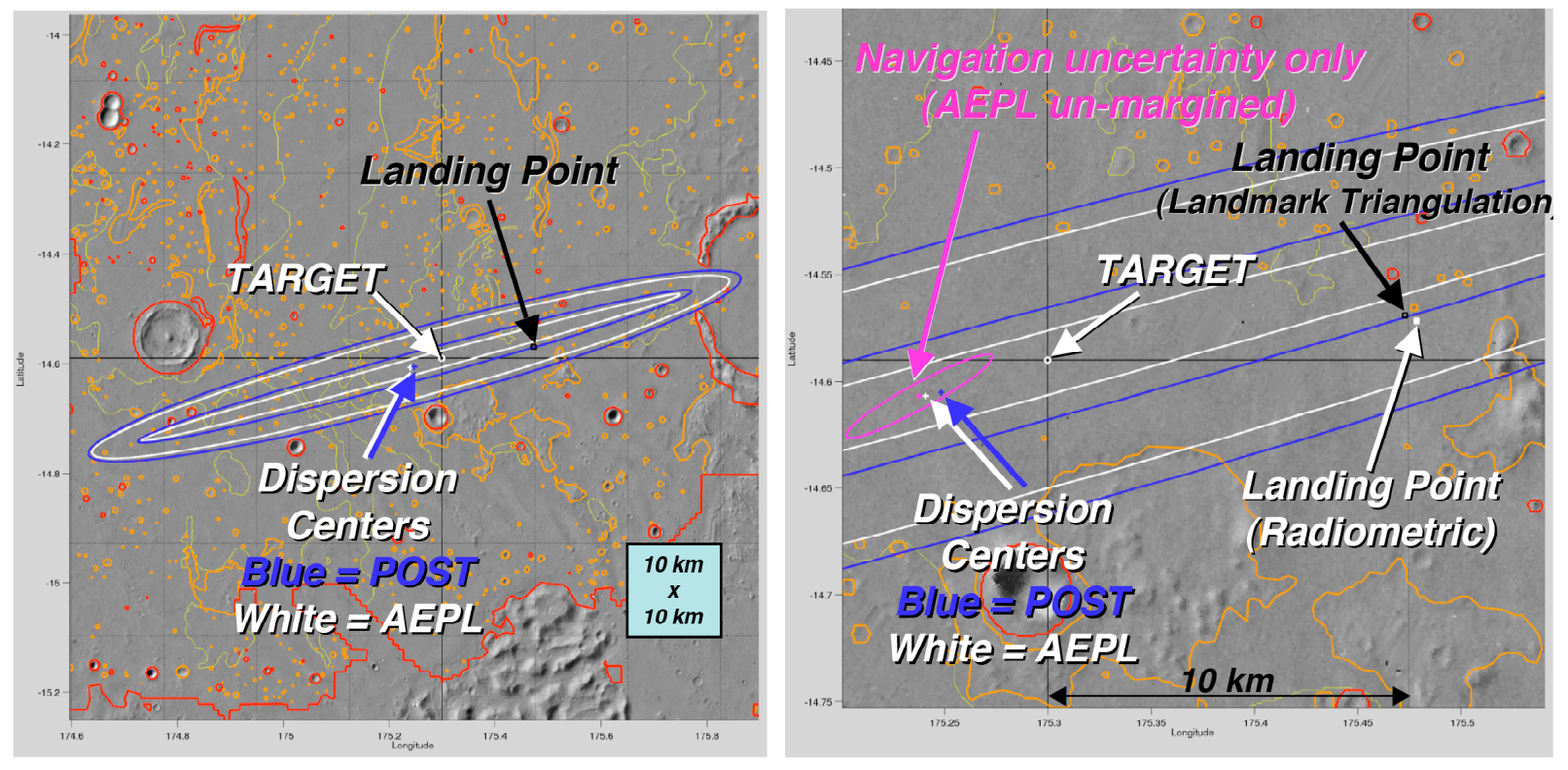

Figure 6: Spirit Final Pre-Entry Dispersions and Final Landing Points

The final landing point was $-14.571892^{\circ}$ areocentric latitude, $175.47848^{\circ}$ East longitude (radiometric estimate), or $-14.5692^{\circ}, 175.4729^{\circ} \mathrm{E}$ (landmark triangulation). ${ }^{\dagger \dagger}$ This was approximately $13.4 \mathrm{~km}$ from the average center point of the final 2-way dispersion ellipses, and $10.1 \mathrm{~km}$ from Target. Spirit's final landing point was located at the very edge of the $99 \%$ POST un-margined ellipse, suggesting that some of the effects considered in the development of the EDL margins (possibly higher than expected winds) may have contributed to the cross-track position.

\section{B. Opportunity}

Opportunity's third TCM was cancelled in part because of its small magnitude, and also to reduce mission activities in the wake of major solar flares which had led to a precautionary commanded reboot of both spacecraft. As a result, prior to the fourth planned TCM, Opportunity was much further from its target than was Spirit during the same mission phase. Figure 7 shows the Opportunity landing dispersions (99\% margined ellipses) as a function of time, starting from Entry - 6 weeks (December 11, 2003 PST) to Entry on January 24, 2004 PST. Each ellipse or group of ellipses is noted with the PST date of the solution and the atmosphere model used. The pre-TCM-4 ellipses (Fig. 7(a)), were generated in AEPL, and are color coded to reflect the different atmosphere models used during this time. Numerous model changes were made during final approach, based on updated TES observations. During this time the dispersions shrank significantly, but the combined effects of altered atmosphere models and updates to orbit determination estimates changed the center points by only about $5 \mathrm{~km}$. For all of these solutions, the Entry/Descent performance was, formally, $0 \%$ in-spec. Mean entry angles were more than $2^{\circ}$ steep, compared with the nominal inertial entry flight path angle of $-11.5^{\circ}$; this put the entry conditions significantly outside the flight system limits of $11.5^{\circ} \pm 0.75^{\circ}$. Formally, the landing $\mathrm{P}(\mathrm{in}-\mathrm{spec})$ was also $0 \%$ because all dispersions lay entirely outside the characterized area.

Opportunity's final maneuver was performed January 16, 2004 PST. Because this was the fourth planned maneuver, it was called TCM-4, although it was only the third maneuver actually performed in the mission. Ellipses 
after TCM-4 are POST estimates, color-coded in Fig. 7(b) to indicate the atmosphere models used at this time. (The "predict" atmosphere density model, used 1/19/2004 - 1/21/2004, was a prediction of what the density model would be at entry; this was essentially the same as the development model (Kass-Schofield v2.4.1) but with larger uncertainties to account for lingering dust storm effects.) Dispersion centers remain quite consistent over this time, varying less than $5 \mathrm{~km}$; this motion reflected the combined result of changes in density models and orbit determination estimates. (Another minor effect was an increase in the targeted parachute deploy dynamic pressure to $750 \mathrm{~N} / \mathrm{m}^{2}$, compared to Opportunity's baseline target of $725 \mathrm{~N} / \mathrm{m}^{2}$. This change was implemented to increase timeline margin. Solutions done after January 16, 2003 include the new targeted dynamic pressure; the effect on the landing point was a movement of less than $500 \mathrm{~m}$ uptrack.) For all these solutions, Entry/Descent P(in-spec) $=100 \%$ and Landing $\mathrm{P}(\mathrm{in}$-spec $)=99 \%$. Probabilities of landing in MOC coverage ranged between $75 \%$ and $76 \%$, and probabilities of landing in low-temperature regions were between $6 \%$ and $12 \%$.

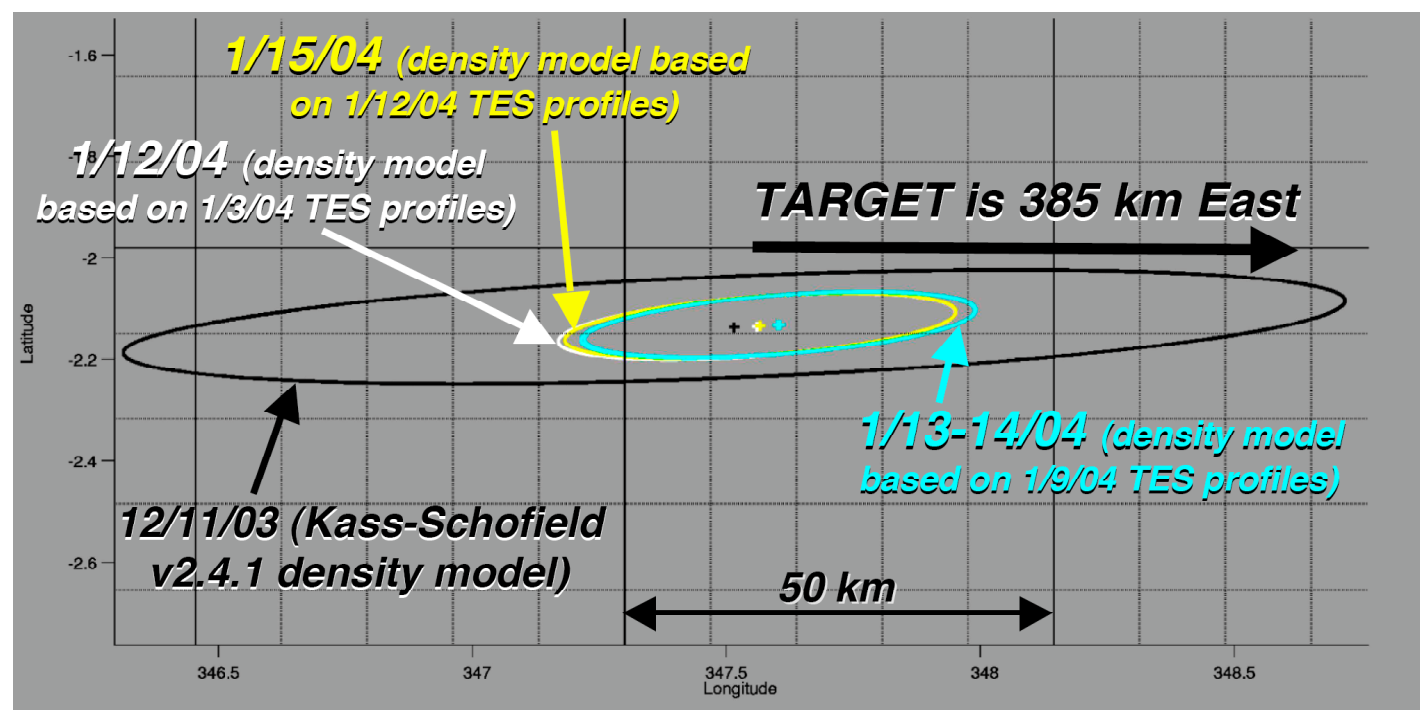

(a) Before TCM-4

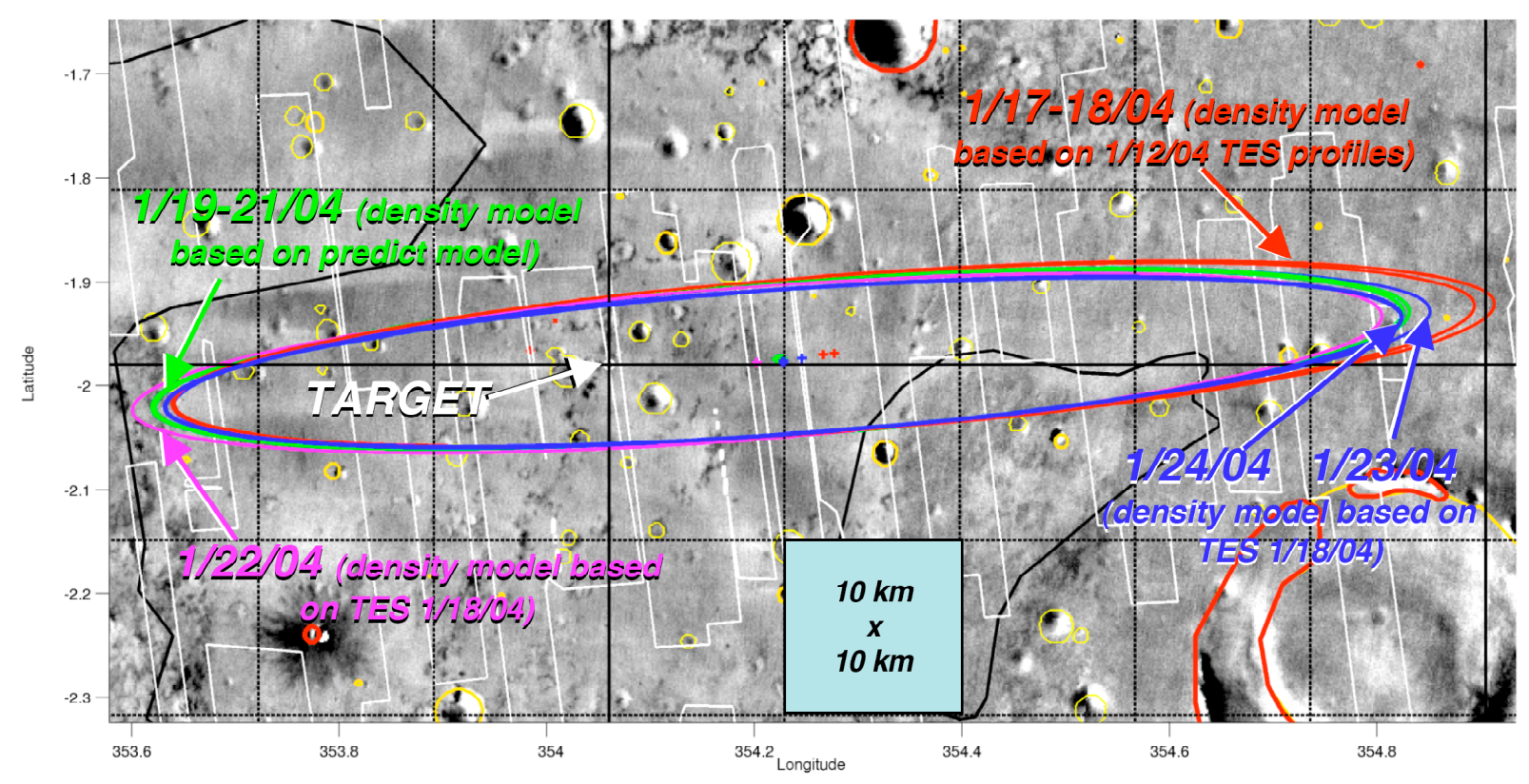

(b) After TCM-4

Figure 7: Opportunity Landing Dispersions During Approach 
Figure 8 shows the final pre-entry POST and AEPL landing dispersions, based on the last 2-way data (data cutoff approximately 105 minutes before entry). As with Spirit, Opportunity's final landing location ${ }^{\text {tat }}$ was determined using radiometric observations $\left(1.948282^{\circ}\right.$ areocentric latitude, $354.47417^{\circ} \mathrm{E}$ longitude $)$ and landmark tracking $\left(-1.9462^{\circ}, 354.4734^{\circ}\right)$; these locations are also shown on Fig. 8. Opportunity landed approximately 14.9 $\mathrm{km}$ distant from the average center points of the final pre-entry ellipses, and $24.6 \mathrm{~km}$ from target. POST and AEPL estimates are in good agreement. The Opportunity landing point lies within the un-margined landing ellipse predicts.
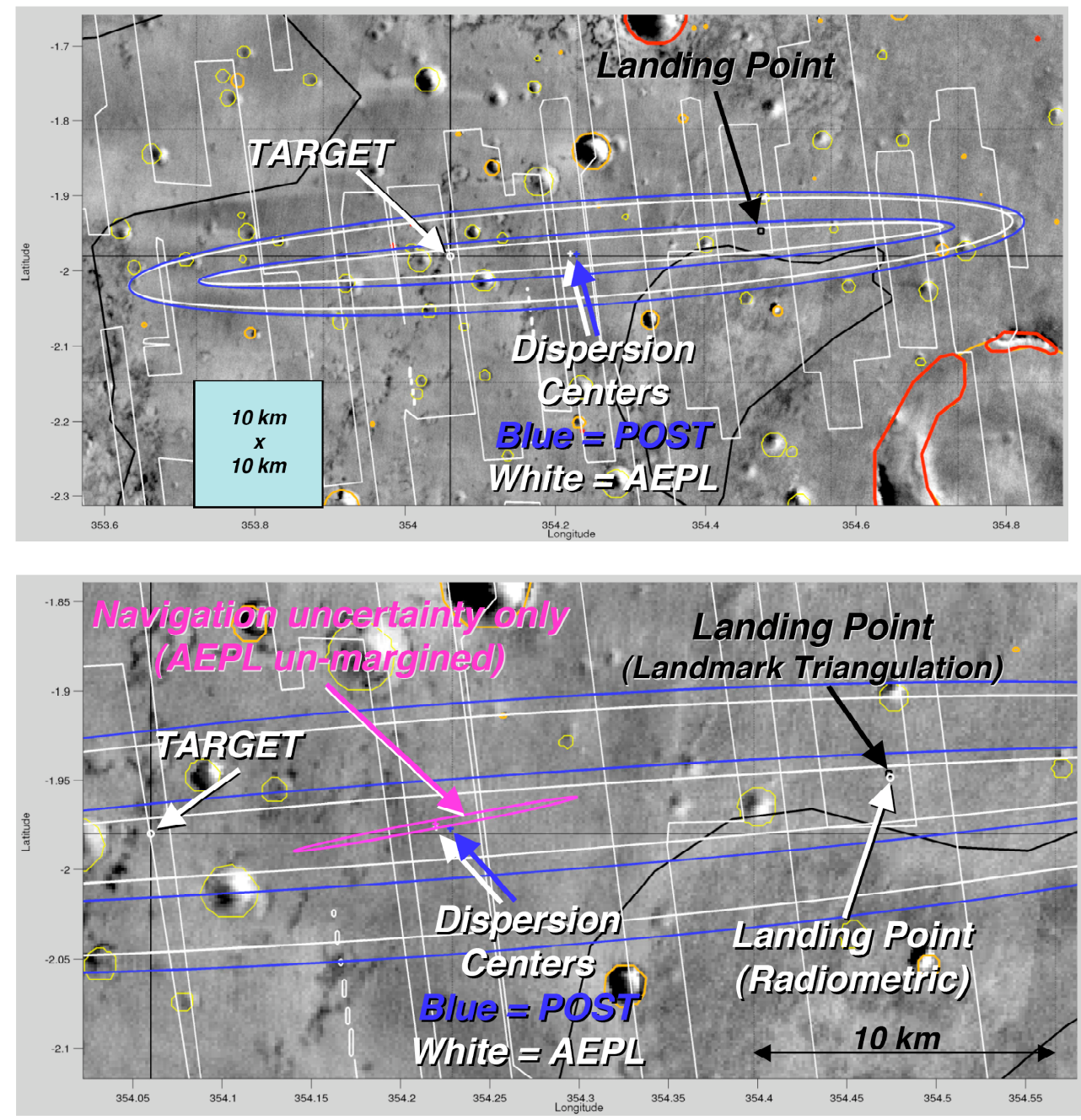

Figure 8: Opportunity Final Pre-Entry Dispersions and Final Landing Points

\section{Conclusion}

The MER Project used an integrated, probabilistic approach to determine landing risk, using hazard maps supplied by the science team, cartographically registered base maps, Monte Carlo analyses (encompassing EDL trajectories and multi-body analyses of flight system interactions with the environment), and a statistical analysis and visualization tool (MarsLS). This suite of tools, processes, and products enabled accurate determination of the inertial location of landing hazards expected to be encountered for both Spirit and Opportunity. More importantly, these tools allowed the consequences of encountering landing hazards to be quantified.

Predictions of landing risk (in-spec probabilities) were evaluated and quickly updated as a function of rapidly evolving navigation and atmospheric uncertainties, during final approach. These data, plus contours of in-spec probabilities, were used as an integral part of the maneuver decision process and the overall targeting strategy. 
Landing locations of both spacecraft were consistent with the final pre-entry predicts of the margined landing dispersion ellipses. Spirit's landing occurred at the very edge of its un-margined landing dispersion ellipse, however, suggesting that some of the effects considered in the development of the EDL margins may have been at work. Landing dispersion predicts during the final weeks of cruise were strongly influenced by updates in atmospheric models.

\section{Acknowledgments}

This research was carried out at the Jet Propulsion Laboratory, California Institute of Technology, under a contract with the National Aeronautics and Space Administration. The authors gratefully acknowledge the contributions of John Michel for developing the algorithm used in the MarsLS statistical analysis package, the MER Navigation Team (Lou D'Amario, team chief), the MER EDL Systems Team (Wayne Lee, team chief), the MER Landing Sites Working Group (Joy Crisp and Mark Adler, leads), and Allan Klumpp for his significant contributions to AEPL development.

\section{References}

${ }^{1}$ Golombek, M. P., Grant, J. A., Parker, T. J., Kass, D. M., Crisp, J. A., Squyres, S. W., Haldemann, A. F. C., Adler, M., Lee, W., Bridges, N. T., Arvidson, R. E., Carr, M. H., Kirk, R. L., Knocke, P. C., Roncoli, R. B., Weitz, C. M., Schofield, J. T., Zurek, R. W., Christensen, P. R., Fergason, R. L., Andesron, F. S., and Rice Jr., J. W., "Selection of the Mars Exploration Rover Landing Sites," Journal of Geophysical Research, Planets, Vol. 108, No. E12, 10 Dec. 2003, pp. ROV 13-1 to ROV 13-48.

2 Brauer, G. L., Cornick, D. E., and Stevenson, R., "Capabilities and Applications of the Program to Optimize Simulated Trajectories (POST)," NASA CR-2770, Feb. 1977.

${ }^{3}$ Kass, D. M., Schofield, J. T., Michaels, T. I., Rafkin, S. C. R., Richardson, M. I., and Toigo, A. D., "Analysis of Atmospheric Mesoscale Models for Entry, Descent, and Landing," Journal of Geophysical Research, Vol. 108, No. E12, 25 Nov. 2003, pp. ROV 31-1 to ROV 31-12.

${ }^{4}$ Portock, B. M., Graat, E. J., McElrath, T. M., Watkins, M. M., and Wawrzyniak, G. G., "Mars Exploration Rovers Cruise Orbit Determination," AIAA/AAS Astrodynamics Specialist Conference, AIAA-04-4981, AIAA, Washington, DC, 2004. (to be published).

${ }^{5}$ Wawrzyniak, G. G., "MarsLS User Guide Version 2.1”, JPL D-24497, 11 Nov. 2003.

${ }^{6}$ Kirk, R., Howington-Kraus, E., Redding, B., Galuszka, D., Hare, T. M., Archinal, B., Soderblom, L. A., and Barrett, J., "High-resolution Topomapping of Candidate MER Landing Sites with Mars Orbiter Camera Narrowangle Images," Journal of Geophysical Research, Vol. 108, No. E12, 26 Dec. 2003, pp. ROV 29-1 to ROV 29-38.

Golombek, M., and Rapp, D., "Size-frequency Distributions of Rocks on Mars and Earth Analog Sites: Implications for Future Landed Missions,” Journal of Geophysical Research, Vol. 102, 1997, pp. 4117-4129.

${ }^{8}$ Beyer, R. A., McEwen, A. S., and Kirk, R. L., "Meter-scale Slopes of Candidate MER Landing Sites from Point Photoclinometry," Journal of Geophysical Research, Vol. 108, No. E12, 4 Dec. 2003, pp. ROV 26-1 to ROV 26-31.

${ }^{9}$ Milam, K. A., Stockstill, K. R., Moersch, J. E., McSween Jr., H. Y., Tornabene, L. L., Ghosh, A., Wyatt, M. B., and Christensen, P. R., "THEMIS Characterization of the MER Gusev Crater Landing Site," Journal of Geophysical Research, Vol. 108, No. E12, 12 Dec. 2003, pp. ROV 19-1 to ROV 19-24,.

${ }^{10}$ Arvidson, R. E., Seelos, F. P., Deal, K., W. Koeppen, Snider, N. O., Kieniewicz, J. M., Hynek, B. M., Mellon, M. T., and Garvin, J. B., "Mantled and exhumed terrains in Terra Meridiani, Mars," Journal of Geophysical Research, Vol. 108, No. E12, 18 Oct. 2003, pp. ROV 14-1 to ROV 14-20.

${ }^{11}$ Rafkin, S. C. R., and Michaels, T. I., "Meteorological Predictions for 2003 Mars Exploration Rover High-priority Landing Sites," Journal of Geophysical Research, Vol. 108, No. E12, 24 Oct. 2003, pp. ROV 32-1 to ROV 32-23.

${ }^{12}$ Neumann, G. A., Rowlands, D. D., Lemoine, F. G., Smith, D. E., and Zuber, M. T., "Crossover Analysis of Mars Orbiter Laser Altimeter Data," Journal of Geophysical Research, Vol. 106, No. E10, 2001, pp. 23, 753-23, 768.

${ }^{13}$ Seidelmann, P. K., Abalakin, V. K., Bursa, M., Davies, M. E., De Bergh, C., Lieske, J. H., Oberst, J., Simon, J. L., Standish, M. E., Stooke, P. and Thomas, P. C., "Report of the IAU/IAG Working Group on Cartographic Coordinates and Rotational Elements of the Planets and Satellites: 2000," Celestial Mechanics and Dynamical Astronomy, Vol. 82, 2002, pp. 83-110.

${ }^{14}$ Lyons, D. T., "MER Project Ground Data System Specification, Vol. 4 - Functional Requriements and Design Document, Mission Design and Navigation Subsystem Mission Design Element,", JPL D-23083, 17 Aug. 2002.

${ }_{16}^{15}$ MATLAB(c), Version 6.1, Release 12.1, The Mathworks, Inc. Natick, MA, 2001.

${ }^{16}$ Potts, C. L., Raofi, B., and Kangas, J. A., "Mars Exploration Rovers Propulsive Maneuver Design," AIAA/AAS Astrodynamics Specialist Conference, AIAA-04-4985, AIAA, Washington, DC, 2004 (to be published). 